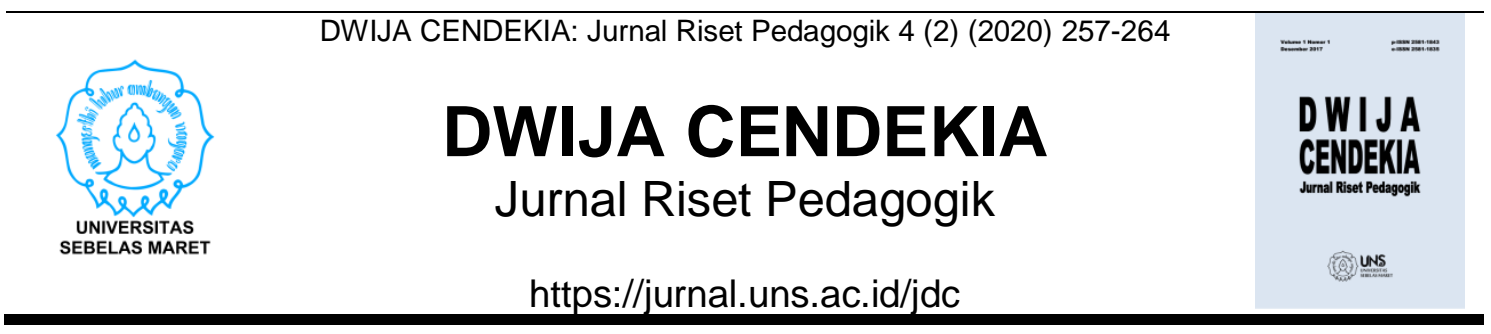

\title{
Aplikasi Pilihan Pendukung Pembelajaran Daring pada Mahasiswa Pendidikan Guru Sekolah Dasar
}

\author{
Prabawati Nurhabibah, Hanikah, Hema Widiawati \\ Universitas Muhammadiyah Cirebon \\ prabawati@umc.ac.id
}

Sejarah Artikel

diterima 28 Oktober 2020 disetujui 20 November 2020 diterbitkan 1 Desember 2020

\begin{abstract}
This study aims to determine the application of online learning support options for Elementary School Teacher Education students. This research method uses a quantitative type with a survey approach. The results of this study indicate that the use of WhatsApp Group is considered to be more effective in supporting online learning. The conclusion in this study is that WhatsApp is more attractive to PGSD students because it is considered the cheapest and easiest compared to other supporting applications because it does not require a large amount of internet quota. WhatsApp Group can be operated simply, personally and safely. Based on the general usability aspect, this application is able to easily send text and voice messages instantly, simply and privately. In addition, it can send photos and videos instantly, make calls for free, and send locations to other users easily.
\end{abstract}

Keywords: online learning, whatsapp group

\section{Abstrak}

Penelitian ini bertujuan untuk mengetahui aplikasi pilihan pendukung pembelajaran daring pada mahasiswa Pendidikan Guru Sekolah Dasar. Metode penelitian ini menggunakan jenis kuantitatif dengan pendekatan survey. Hasil penelitian ini menunjukkan penggunaan WhatsApp Group dinilai lebih efektif untuk mendukung pembelajaran daring. Kesimpulan dalam penelitian ini adalah WhatsApp lebih diminati oleh mahasiswa PGSD karena dianggap paling murah dan mudah dibandingkan dengan aplikasi pendukung lainnya karena tidak membutuhkan kuota internet dalam jumlah besar. WhatsApp Group dapat dioperasikan secara sederhana, personal, dan aman. Berdasarkan aspek general usability aplikasi ini mampu dengan mudah untuk mengirim pesan teks maupun suara secara instan, sederhana dan pribadi. Selain itu dapat mengirim foto dan video secara instan, membuat panggilan secara gratis, serta mengirim lokasi pada pengguna lain dengan mudah.

Kata kunci : pembelajaran daring, whatsapp gruop 


\section{PENDAHULUAN}

Program studi Pendidian Guru Sekolah Dasar (PGSD) Universitas Muhammadiyah Cirebon saat ini memiliki kelas reguler maupun karyawan dengan jumlah aktif mahasiswa sebanyak 288. Dengan diterbitkannya surat edaran mengenai Work From Home (WFH) dan Study From Home (SFH) di masa Pandemi Covid-19, mewajibkan seluruh pembelajaran dilakukan dengan jarak jauh melalui beberapa aplikasi pendukung yang ditawarkan seperti $e$ learning, Google Classroom, Edmodo, Zoom, Google Meet, WhatsApp dan aplikasi pendukung lainnya. Beragam platform pembelajaran digital tersebut digunakan sebagai wujud usaha untuk menghasilkan pembelajaran yang berkualitas walaupun dilakukan dengan metode daring.

Metode pembelajaran dengan memanfaatkan teknologi melalui dalam jaringan (daring), memiliki tantangan tersendiri di saat mewabahnya pandemi saat ini. Terdapat beberapa keunggulan dan kelemahan dalam pembelajaran daring. Menurut Sugandi (2020) beberapa keunggulan dari pembelajaran daring adalah efektivitas waktu dan tempat. Selain itu materi yang sudah diajarkan dapat diulang berkali-kali oleh mahasiswa sampai materi tersebut dipahami dengan baik. Keuntungan lain yang didapatkan ketika melakukan pembelajaran daring adalah pembelajaran dapat dilakukan dengan menganut konsep merdeka belajar yaitu anytime and anywhere.

$$
\text { Kelemahan }
$$

dalam

pembelajaran daring menurut Sugandi (2020) di antaranya adalah Dosen sulit mengontrol keseriusan belajar mahasiswa karena interaksi di antara keduanya menjadi terbatas. Gavrilova
(2006) menambahkan bahwa kekurangan dalam pembelajaran daring adalah pembelajaran membutuhkan peralatan tambahan lebih. Kebutuhan peralatan dan teknis seperti komputer, gawai, paket data internet menjadi kendala bagi yang tinggal di pelosok dan baru menerapkan sistem pembelajaran daring.

\section{a. Pembelajaran Daring}

Kegiatan pembelajaran yang dilakukan secara jarak jauh dengan berbantuan layanan internet sebagai salah satu upaya untuk mengganti pertemuan tatap muka adalah pengertian pembelajaran daring. Terdapat spesifikasi dan standar untuk mengimplementasikan learning content agar pebelajaran daring lebih bermutu menurut Bilfaqih dan Qomarudin (2015: 3), diantaranya sebagai berikut:

1. Accesibility, kemampuan untuk mencari dan mengakses komponen instruksional dari suatu lokasi remote dan mengirimkannya ke banyak lokasi lain.

2. Adaptability, kemampuan untuk menyesuaikan instruksi kepada kebutuhan pribadi dan organisasi.

3. Affordability, kemampuan untuk meningkatkan efisiensi dan produktivitas dalam pengiriman instruksi.

4. Durability, kemampuan bertahan dari perkembangan dan perubahan teknologi tanpa banyak mengeluarkan biaya untuk mendesai, mengkonfigurasi serta penyimpanan ulang.

5. Interoperability, kemampuan untuk mengambil komponen-komponen instruksional yang dikembangkan 
pada suatu lokasi dengan kelengkapan tool atau platformnya dan menggunakannya di tempat lain dengan tool atau platform yang berbeda.

6. Reusability, kemudahan menggabungkan komponenkomponen instruksional dalam aplikasi-aplikasi dan kontekskonteks yang berbeda dan bertingkat.

Karakteristik inilah yang memberikan gambaran nilai tambah pada materi pembelajaran daring yang dikembangkan mengikuti standar.

Kusyarina (Kompasiana: 2020) mengemukakan bahwa pembelajaran daring yang dilakukan tentu saja menganut konsep merdeka belajar yang selama ini sering didengungkan oleh Menteri Pendidikan yaitu Nadiem Makariem bahwa belajar dapat dilakukan dengan cara apapun, kapanpun, dan dimanapun. Mahasiswa diberi keleluasaan untuk berinteraksi dengan dosen dengan berbagai alternatif pilihan seperti Video Call, Zoom, Pesan teks maupun audio, dan berbagai jenis media lain yang tersedia melalui aplikasi secara elektronik.

Pemanfaatan sosial media sebagai sarana pembelajaran juga dapat menambah kreativitas mahasiswa dalam mengakses dan mempelajari bahan ajar, berdiskusi dan berbagi dengan sesama teman, mengerjakan tugas, serta memberikan feedback terhadap materi pembelajaran. Hal ini dapat berjalan jika ada proses bimbingan dan panduan yang diberikan oleh dosen kepada mahasiswa secara daring.

Sebelum memulai pembelajaran daring, hal-hal yang perlu dipersiapkan dosen diantaranya adalah modul atau buku pedoman, materi presentasi, video mengenai penjelasan materi yang telah direkam sebelumnya, rekaman audio mengenai penjelasan materi presentasi, dan beberapa media pendukung lainnya yang dapat menunjang kelancaran pembelajaran daring.

Perencanaan

perkuliahan dengan moda daring sama dengan perancangan perkuliahan tatap muka. Dalam satu semester, perkuliahan di semua prodi pada kampus UMC semuanya menggunakan 14 kali pertemuan, tidak termasuk pertemuan UTS dan UAS. Oleh karena itu, dalam pertemuan pembelajaran daring juga membutuhkan 14 kali pertemuan agar materi perkuliahan dapat terlaksana dan tersampaikan dengan baik. Sebenarnya tidak ada perbedaan yang terlalu mendasar mengenai jumlah pertemuan antara tatap muka maupun daring, yang membedakan hanyalah medianya saja yaitu pembelajaran daring harus menggunakan media internet sebagai penghubungnya.

\section{b. Media Pendukung Pembelajaran Daring}

Pembelajaran daring sejatinya dapat membuat dosen untuk berkreasi dan berinovasi dalam membuat konten pembelajaran yang menarik dan dapat dipahami oleh mahasiswa. Menurut Kuntarto (2017: 101) istilah model pembelajaran daring atau Online Learning Models (OLM), pada awalnya digunakan untuk menggambarkan sistem belajar yang memanfaatkan teknologi internet berbasis komputer (computer-based learning/ CBL). Dalam perkembangan selanjutnya, fungsi komputer telah digantikan oleh telepon seluler atau gawai. Dengan pengalihan dari komputer ke gawai pembelajaran dapat berlangsung dengan fleksibel dan mudah.

Perkembangan dunia digital yang begitu pesat haruslah 
dimanfaatkan dengan bijaksana oleh dosen dan mahasiswa untuk tetap dapat berkomunikasi dan terhubung walaupun tidak dapat melaksanakan pertemuan tatap muka di kelas. Pendidikan tinggi menurut Huda (dalam Darmalakssana, 2020) sangat membutuhkan suatu lingkungan belajar modern.

Sejak 10 tahun terakhir aplikasi WhatsApp telah berperan penting dalam dunia komunikasi digital masyarakat Indonesia khusunya kalangan akademisi di Perguruan Tinggi. Beberapa hasil penelitian menurut Allagui (dalam Darmalaksana, 2020) menunjukkan bahwa penggunaan WhatsApp di kelas dapat meningkatkan motivasi mahasiswa pendidikan tinggi dalam hal keterampilan menulis. Sebagian besar mahasiswa menyukai mobile learning melalui WhatsApp karena general usability yang ditawarkan dapat memudahkan penggunanya untuk melakukan beragam aktivitas komunikasi mulai dari percakapan teks, audio, video call, maupun berbagi lokasi pengguna.

Dengan adanya kemajuan pesat dunia digital melalui terciptanya beragam gawai pintar yang dapat memobilisasi kegiatan komunikasi dengan WhatsApp, tidak menutup kemungkinan bahwa platform ini dapat digunakan secara luas untuk ruang lingkup pendidikan.

$$
\text { Aplikasi pesan singkat }
$$

WhatsApp dioperasikan dengan menggunakan paket data Internet pengguna yang ada untuk membantu mereka membangun jaringan secara sosial dalam waktu nyata (WhatsApp, 2010). WhatsApp memberi pengguna online kemampuan untuk mengirim dan menerima. Platform WhatsApp memiliki fitur kolaboratif berikut (WhatsApp, 2010).

1. Memberi mahasiswa kemampuan untuk bertukar pesan teks, gambar, video, dan catatan suara ke jejaring sosial atau grup dan kontak mereka.

2. Memberi siswa dan dosen kemampuan untuk membuat grup (grup jaringan sosial) yang mendukung interaksi sosial. Anggota dapat terlibat dalam forum diskusi.

3. WhatsApp memberikan kemampuan bagi mahasiswa untuk mengirim pesan tanpa batas. Aplikasi ini menggunakan Internet minimal 3G/ EDGE.

Dalam keadaan serba tidak pasti karena adanya pandemi covid-19 saat ini menyebabkan beberapa masalah sosial dan ekonomi. Termasuk kemampuan mahasiswa dalam membeli sejumlah kuota internet untuk keberlangsungan pembelajaran daring.

Berbagai platform sebetulnya dapat dimanfaatkan untuk mendukung pembelajaran daring pada prodi PGSD UMC seperti Zoom, Google Meet, video unggahan dari Dosen maupun video penunjang dari Youtube. Namun dari beberapa alternatif tersebut dibutuhkan sejumlah kuota internet dengan jumlah yang besar. Sehingga tidak begitu diminati oleh sejumlah mahasiswa dengan kondisi perekonoman menengah.

Penelitian ini bertujuan untuk membandingkan aplikasi pilihan pendukung pembelajaran daring yang dianggap paling efektif dengan mempertimbangkan faktor murah dan mudah berdasarkan pilihan mahasiswa prodi PGSD UMC. 


\section{METODE}

Waktu pelaksanaan penelitian pada semester genap tahun akademik 2019/2020 di mulai dari bulan AprilJuni 2020 dengan populasi Mahasiswa PGSD Semester 2 di Universitas Muhammadiyah Cirebon jumlah responden 116 mahasiswa PGSD UMC.

Metode penelitian yang penulis gunakan adalah menggunakan metode kuantitatif dengan pendekatan survey. Menurut Sugiyono (2017) menyatakan bahwa "Metode kuantitatif dapat diartikan sebagai metode positivistik karena berlandaskan pada filsafat positivisme. Metode ini sebagai metode ilmiah karena telah memenuhi kaidah-kaidah ilmiah yaitu konkrit/empiris, objektif, rasional, dan sistematis".

Adapun teknik pengumpulan data yang dilakukan penulis dalam penelitian ini adalah penelitian lapangan (Field Research). Teknik pengumpulan data merupakan caracara yang dilakukan untuk memperoleh data dan keteranganketerangan yang diperlukan dalam penelitian. (Sugiyono, 2017: 137). Teknik Penelitian Lapangan (Field Research) adalah penelitian yang dimaksudkan untuk memperoleh data primer yaitu data yang diperoleh melalui kuesioner sebagai instrumen pada penelitian ini. Kuesioner pada penelitian ini bertujuan untuk pengumpulan data dengan dengan ara membuat daftar pertanyaan yang berkaitan dengan objek yang diteliti, diberikan kepada responden. Adapun daftar pertanyaan mengenai gambaran umum, perhatian dan pendapat responden mengenai beberapa pilihan aplikasi pendukung untuk pembelajaran daring melalui beberapa persepsi pilihan mahasiswa di PGSD UMC.

Analisis data yang digunakan adalah analisis deskriptif. Menurut Sugiyono (2017: 22) analisis deskriptif merupakan analisis yang mengemukakan tentang data diri responden, yang diperoleh dari jawaban responden melalui kuesioner. Kemudian, data yang diperoleh dari jawaban responden tersebut dihitung presentasinya. Analisis deskriptif dalam penelitian pada dasarnya mengemukakan proses transformasi data penelitian dalam bentuk tabulasi sehingga mudah dipahami dan diinterpretasikan.

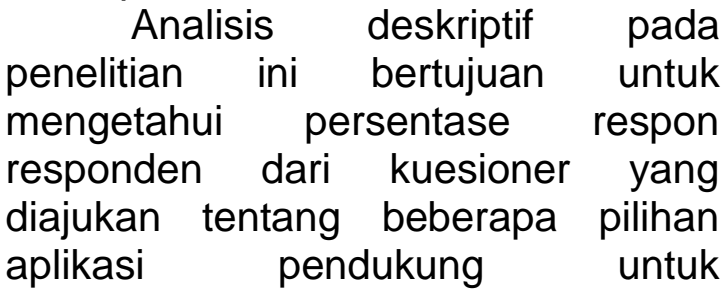
pembelajaran daring melalui beberapa persepsi pilihan mahasiswa di PGSD UMC. Mendeskripsikan atau memberikan gambaran terhadap objek yang diteliti melalui data sampel populasi. Sebagaimana adanya, tanpa melakukan analisis dan membuat kesimpulan yang berlaku umum. Setelah adanya analisis data antara data di lapangan kemudian diadakan perhitungan hasil kuesioner peneliti, menyusun data secara sistematik melalui grafik, agar hasil analisis peneliti dapat teruji dan dapat ditarik kesimpulan. Penelitian ini melihat aplikasi pilihan pendukung pembelajaran daring pada mahasiswa Program studi PGSD di Univeristas Muhammadiyah Cirebon. Aplikasi tersebut yang dianggap di pilih oleh mahasiswa untuk mendukung pembelajaran Online di masa Pandemi covid-19. 


\section{PEMBAHASAN}

Berdasarkan hasil kuesioner yang telah disebar melalui Google Form dengan jumlah responden 116 terdapat 56, 9\% mahasiswa lebih memilih WAG sebagai media yang paling efektif untuk mendukung pembelajaran daring. Kemudian aplikasi pilihan kedua adalah Zoom

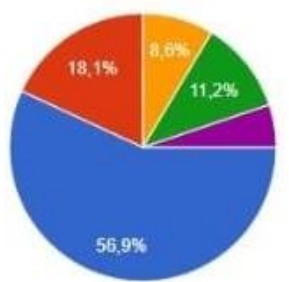

dengan peringkat kedua sebanyak 18 , $1 \%$, ketiga diduduki oleh video unggahan dari dosen, dan 8, 6\% Google Meet, dan 5, 2\% ditempati oleh media digital lainnya. Hasil persentase perbandingan pilihan pembelajaran daring bisa dilihat di dalam diagram berikut ini:

\section{Gambar 1. Hasil persentase perbandingan pilihan pembelajaran daring}

Berdasarkan hasil kuesioner tersebut, pemilihan WAG dianggap paling efektif dibandingkan dengan aplikasi pendukung lainnya. Pemilihan WAG tersebut berdasarkan pendapat sebagian besar responden menyatakan bahwa WAG dalam penggunaannya lebih mudah dan simpel. Hal tersebut sejalan dengan Beberapa hasil penelitian menurut Allagui (dalam Darmalaksana, 2020) menunjukkan bahwa sebagian besar mahasiswa menyukai mobile learning melalui WhatsApp karena general usability yang ditawarkan dapat memudahkan penggunanya untuk melakukan beragam aktivitas komunikasi mulai dari percakapan teks, audio, video call, maupun berbagi lokasi pengguna. Aplikasi Whats App (WA) juga merupakan platform dengan pengguna terbanyak dan sesuai dengan slogannya yaitu sederhana, personal, dan aman. Aplikasi ini juga memudahkan interaksi dua arah antara dosen dengan mahasiswa sehingga pembelajaran menjadi interaktif dan jika ada salah satu mahasiswa yang bertanya dosen bisa langsung menanggapinya.

Sedangkan jika dibandingkan dengan aplikasi lainnya seperti zoom, google meet dan lainnya sebagian besar responden menganggap bahwa aplikasi tersebut kurang efektif dan kurang simpel untuk digunakan karena disesuaikan dengan situasi dan kondisi mahasiswa, dan juga ada rasa kekhawatiran bocornya privasi dalam proses penggunan aplikasi tersebbut. Hal tersebut sejalan dengan pernyataan Iskandar dalam Irvan (2020) yang menyatakan tentang kelemahan zoom antara lain:

1. Ekspos data dikirim ke facebook.

2. Isu penggunaan enkripsi

3. Rentan pencurian data

4. Gangguan malware

5. Komputer zombie

Berdasarkan kekhawatiran dari kekurangan tersebut lebih banyak mahasiswa yang memilih WAG sebagai alternatif terbaik guna proses pembelajaran. 


\section{SIMPULAN}

Simpulan dalam penelitian ini adalah Whatsapp terbukti efektif dan efisien untuk mendukung pembelajaran daring mahasiswa PGSD. Efektivitas itu dapat dirasakan dengan melihat hasil dari persentase pemilihan media pembelajaran elektronik yang sebagian besar memilih menggunakan WAG yaitu $56,9 \%$. Selain itu pemilihan WAG dianggap paling efektif dibandingkan dengan aplikasi pendukung lainnya seperti zoom karena dapat menyebabkan ekspos data dikirim ke facebook, isu penggunaan enkripsi, rentan pencurian data, gangguan malware, dan komputer zombie.

Berdasarkan aspek general usability aplikasi ini mampu dengan mudah dan murah untuk mengirim pesan teks maupun suara secara instan, sederhana dan pribadi. Selain itu dapat mengirim foto dan video secara instan, membuat panggilan secara gratis, serta mengirim lokasi pada pengguna lain dengan mudah.

\section{DAFTAR PUSTAKA}

Amry, Aicha Blech. (2014). The Impact of Whatsapp Mobile Social Learning on the Achievement and Attitudes of Female Students Compared with Face to Face Learning in the Classroom. Departement of Educational Technology, Faculty of Education, Taibah University.

Bilfaqih dan Qomarudin. (2015). Esensi Penyusunan Materi Daring. Yogyakarta: Deepublish.

Darmalaksana, Wahyudin. (2020). WhatsApp Kuliah Mobile. UIN Sunan Gunung Djati Bandung. (Unpublished) http://digilib.uinsgd.ac.id/id/epri $\mathrm{nt} / 30354$

Irvan. (2020). Zoom aman bagi pengguna? Review kelemahan dan panduan praktis preventif. Pendidikan Matematika, STKIP
Muhammadiyah Bone. https://www.researchgate.net/p ublication/341070422_Zoom_a man_bagi_pengguna_Review_ kelemahan_dan_panduan_prak tis_preventif/link/5eabba7ca6fd cc70509df9dc/download

Kuntarto, E. \& Asyhar, R. (2017). "Pengembangan Model Pembelajaran Blended Learning Pada Aspek Learning Design dengan Platform Media Sosial Online Sebagai Pendukung Perkuliahan Mahasiswa". Repository Unja. Https://repository.unja.ac.id/cgi/ users/ home?screen=EPrint::View\&ep rintid $=626$.

Kuntatro, Eko. (2017). "Keefektifan Model Pembelajaran Daring dalam Perkuliahan Bahasa Indonesia di Perguruan Tinggi" dalam jurnal Indonesian Languange Education and Literatue, Vol. 3, No.1 
DOI:http://dx.doi.org/10.24235/il eal.v3il.1820.

Kusyarina, Nila. (2020). Sistem Belajar Daring, Anak Merdeka (Belajar/ Bermain) saat Pandemi. 10 Juni 2020: Kompasiana.

Sugandi, Budi. (2020). Belajar daring di tengah balada corona. https://www.antaranews.com/b erita/1398006/belajar-daring-ditengah-balada-corona

Sugiyono. (2017). Metode Penelitian Kuantitatif, Kualitatif, dan R\&D. Bandung : Alvabeta

WhatsApp. (2010). Retrieved from BlackBerry App World:

WhatsApp. (2010). BlackBerry App World. R

Zukaida, Hadi. (2015). Pembelajaran Angklung melalui metode Handsign pada Mata Pelajaran Angklung di MI Al-Lathif Bandung.

http://repository.upi.edu/22807/ 6/S_PSM_1002151_Chapter3. pdf 